DOI https://doi.org/10.18551/rjoas.2017-12.31

\title{
INFLATION FORECAST IN INDONESIA: EXPENDITURE GROUPS OF HOUSING, WATER, ELECTRICITY, GAS, AND FUEL USING TIME SERIES ANALYSIS APPROACH
}

\author{
Murodah Chulliyatul* \\ Postgraduate School, Airlangga University, Surabaya, Indonesia \\ Sediono, Ana Elly \\ Faculty of Science and Technology, Airlangga University, Surabaya, Indonesia \\ *E-mail: chulliyatul9329@gmail.com
}

\begin{abstract}
Inflation stability is a prerequisite for sustainable economic growth. Appropriate information that can be used to manage and control the inflation rate is future inflation prediction. Expenditure groups of housing, water, electricity, gas and fuel have major commodities which have strong influence on inflation spike, so that it is necessary to give more attention in the inflation rate management for those expenditure groups. The aim of this research is to perform inflation model and forecast using time series analysis approach. The data used in this research are Indonesian's monthly inflation data for the expenditure groups of housing, water, electricity, gas and fuel which are taken from BPS Indonesia.
\end{abstract}

\section{KEY WORDS}

Inflation, time series, ARIMA, MSE.

Inflation stability is a prerequisite for sustainable economic growth, which in turn will provide benefits for the improvement of social welfare (Lusia and Suhartono, 2011). Indonesia has a higher inflation value from neighboring countries and is the country with the highest inflation rate in ASEAN since 2013 (Akbarwati, 2015). There are several commodities that play a major role in the inflation rate in Indonesia, including electricity, water and fuel which contribute the highest inflation rate (BPS, 2014). These commodities are joined into the inflation in expenditure groups of housing, water, electricity, gas and fuel. BPS data show that the expenditure groups have the highest basic weight value in general measurement of inflation which reaches $25.41 \%$ (Wibowo, 2014).

One of inflation management is to forecast the inflation, (Stock and Watson, 1999). Inflation forecast is a bridge to know the inflation value of the following period, (Faust and Wright, 2013). Obtaining an accurate value of inflation forecast will be important for many parties; namely to establish monetary and fiscal policies, make investment decisions and discover the extent of people's purchasing power (Tzavalis and Wickens, 1996).

Previous research on inflation conducted by Lusia and Suhartono (2011) had a general inflation forecast in Indonesia regardless of certain sub-commodities. In addition, another research conducted by Cahyuni (2012) had a model for inflation in foodstuffs group. Previous research had not specifically addressed the inflation for expenditure groups of housing, water, electricity, gas and fuel. Actually, the groups have a significant impact on the development of Indonesian economy.

Based on the above description, the authors are having monthly inflation forecast in Indonesia to the expenditure groups of housing, water, electricity, gas and fuel by time series analysis approach (McCleary et al., 1980). The inflation values of the following period can be predicted by using time series analysis. The model used in this research is autoregressive integrated moving average (ARIMA). This model assumes that the residual model is white noise and normal distribution. Model estimation is conducted by using Maximum Likelihood Estimator method. 
Sketchily, inflation is defined as the rise of prices generally and continuously. The indicator used to measure the inflation rate in Indonesia is Consumer Price Index (CPI). The calculation of inflation for each month is:

$$
I R_{n}=\frac{I_{n}-I_{(n-1)}}{I_{(n-1)}} \times 100
$$

Where:

$I R_{n}=$ Inflation rate at month $n$;

$I_{n}=$ Consumer Price Index at month $n$;

$I_{(n-1)}=$ Consumer Price Index at month $(n-1)$.

ARIMA is a model that completely ignores independent variables in making the forecast. ARIMA uses past and present values of dependent variable to generate the forecast. The ARIMA model $(p, d, q)$ is a forecasting model for time series data which has $p$ level of autoregressive model, q level of moving average, and d-difference is taken to make it stationary. The general form of ARIMA equation $(p, d, q)$ is:

$$
\phi_{p}(B)(1-B)^{d} Z_{t}=\theta_{q}(B) \varepsilon_{t}
$$

The complete ARIMA ( $p, d, q)$ model can be written as follows:

$$
\begin{gathered}
W_{t}=\phi_{1} W_{t-1}+\cdots+\phi_{p} W_{t-p}-\theta_{1} \varepsilon_{t-1}-\cdots-\theta_{q} \varepsilon_{t-q}+\varepsilon_{t} \\
W_{t}=(1-B)^{d} Z_{t}
\end{gathered}
$$

\section{METHODS OF RESEARCH}

The data used in this research are Indonesian's monthly inflation data for the expenditure groups of housing, water, electricity, gas and fuel from February 2009 to January 2015. The data source is secondary data. The data are obtained from the Central Bureau of Statistics Indonesia (BPS). The steps of data analysis can be explained as follow: identify the stationarity of the data to the mean and variance. If the data are not stationary to variance then Box-Cox transformation is conducted. Meanwhile, if data is not stationary to mean then differencing is conducted; identify the model by looking at ACF and PACF plots based on the data that have already been stationary; conduct the estimation of model parameters by using Maximum Likelihood Estimator method; conduct the significance testing of the parameters with the t-test; conduct the diagnostic checking to see if the residual model is white noise through Ljung Box test and if it has a normal distribution through Kolmogorov-Smirnov test; choose the best model based on the lowest forecasting result of MSE.

\section{RESULTS AND DISCUSSION}

Identification of Data Stationarity. Identification of stationarity is conducted firstly by plotting the data.

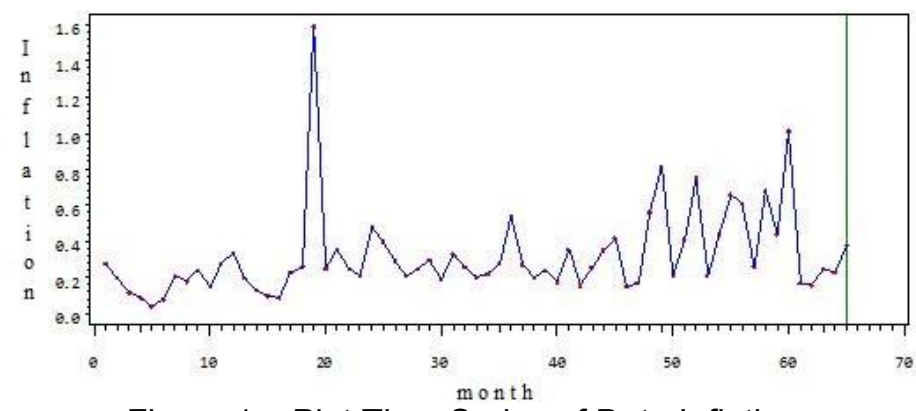

Figure 1 - Plot Time Series of Data Inflation 
Plotting is conducted to see if the data has a trend and has met the stationarity in the mean and variance. Identification of data stationarity can be obtained from the time series plot diagram in figure 1.

Based on the figure above, the data pattern shows an unstable in the mean because the plot shows a fluctuated pattern. The variance pattern of the data is not stationary as well, because the variance width of the data is quite varied. The data is not stationary then it necessary to conduct transformation and differencing to make the mean and variance stationary. The first step of data stationarity is to look at the value in the Box-Cox transformation diagram which is displayed in the following figure.

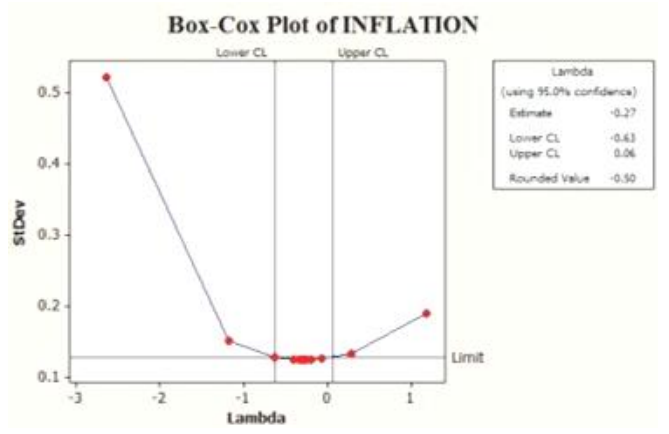

Figure 2 - Box-Cox Transformation Diagram

The Box-Cox transformation diagram shows a value of -0.5 , so the data are transformed by using the transformation formula. The time series plot for the transformation data is displayed in the following figure.

Inflation of Housing, Water, Electricity Gas and Fuel Comodities

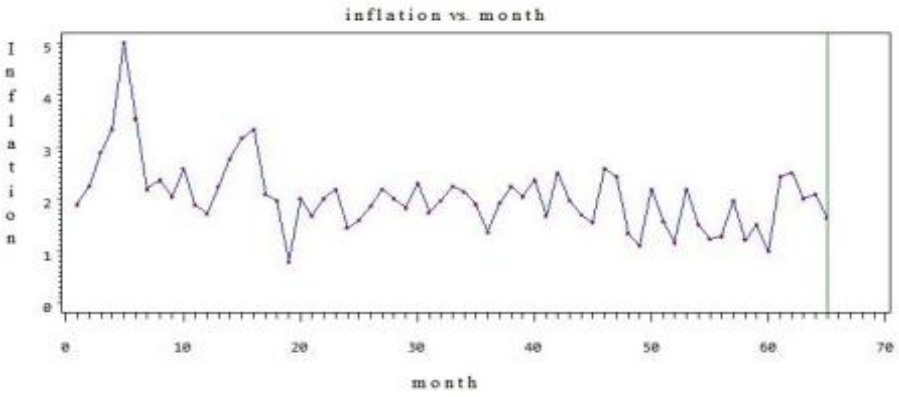

Figure 3 - Plot Time Series of Transformation Data

Next, to see the data stationarity in the mean should check the ACF plot of transformation data. The ACF plot of transformation data is displayed in the following table.

Table 1 - Plot ACF Data Transformation

\begin{tabular}{|c|c|c|c|c|c|}
\hline \multicolumn{6}{|c|}{ Autocorrelations } \\
\hline Lag & Covariance & Correlation & -19876543210 & 01234567891 & Std Error \\
\hline 0 & 0.437615 & 1.00000 & | & $|* * * * * * * * * * * * * * * * * * * * *|$ & $\theta$ \\
\hline 1 & 0.226179 & 0.51684 & . & |*********** & 0.124035 \\
\hline 2 & 0.111420 & 0.25461 & . & |*****. & 0.153636 \\
\hline 3 & 0.049904 & 0.11404 & . & |**. & 0.159995 \\
\hline 4 & 0.044298 & 0.10123 & . & |** & 0.161241 \\
\hline 5 & 0.046278 & 0.10575 & . & |** & 0.162216 \\
\hline 6 & 0.024657 & 0.05634 & . & |* & 0.163273 \\
\hline 7 & 0.047035 & 0.10748 & . & j** & 0.163572 \\
\hline 8 & 0.044422 & 0.10151 & . & |** & 0.164655 \\
\hline 9 & 0.039983 & 0.09137 & . & |** & 0.165615 \\
\hline 10 & 0.092059 & 0.21037 & . & $\mid * * * *$. & 0.166388 \\
\hline 11 & 0.097472 & 0.22274 & . & [**** . & 0.170431 \\
\hline 12 & 0.054258 & 0.12399 & . & |** & 0.174852 \\
\hline 13 & -0.011055 & -.02526 & $* 1$ & . & 0.176199 \\
\hline 14 & -0.069256 & -.15826 & $* * * \mid$ & . & 0.176255 \\
\hline 15 & -0.028050 & -.06410 & $* 1$ & . & 0.178428 \\
\hline 16 & -0.029129 & -.06656 & $* 1$ & . & 0.178782 \\
\hline
\end{tabular}


The table above shows that the transformation data have an ACF plot that slowly and exponentially decreases, so the data have not been stationary in the mean and then differencing lag 1 is conducted to the transformation data. The plot time series for differencing lag 1 data is displayed in the following figure.

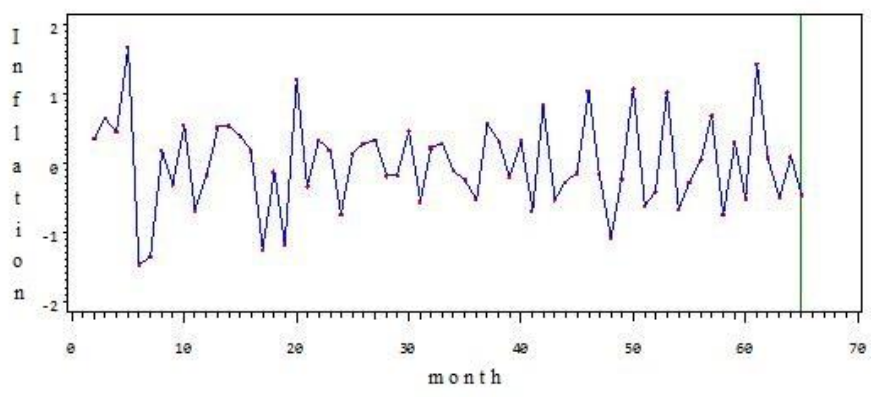

Figure 4 - Plot Time Series of Differencing Lag 1 Data

Next, ACF and PACF plot are checked on the differencing lag 1 data. ACF plot of differencing lag 1 data is displayed in the following table:

Table 2 - ACF Plot of Differencing Lag 1 Data

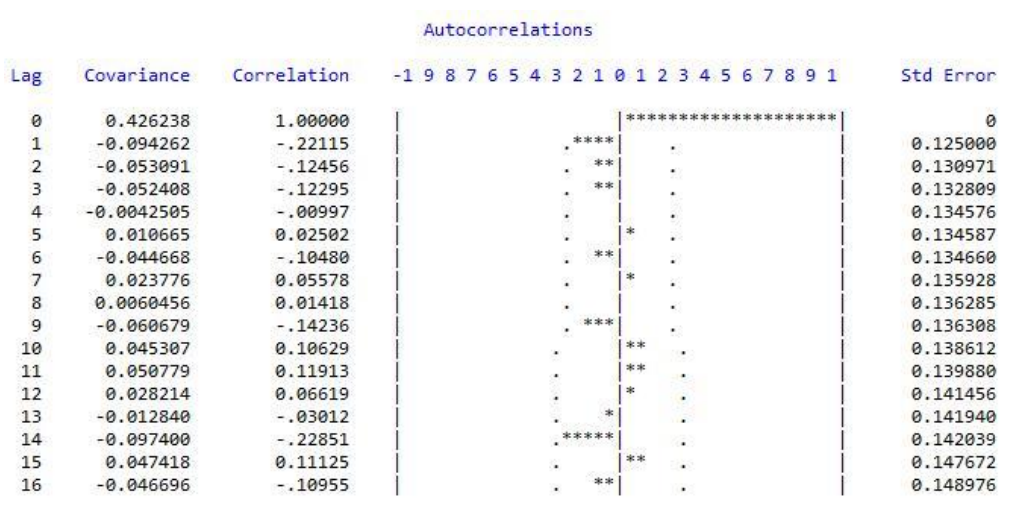

PACF plot of differencing lag 1 data is displayed in the following table:

Table 3 - PACF Plot of Differencing Lag 1 Data

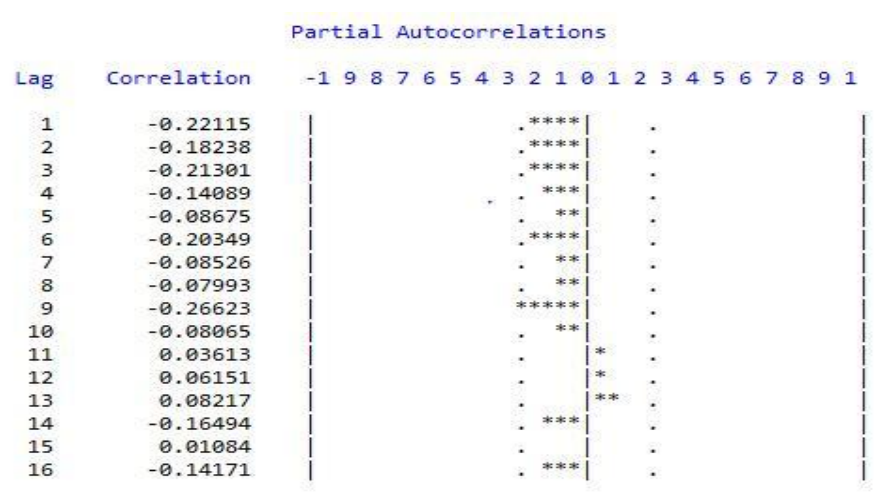

ACF and PACF plots of differencing lag 1 data show both ACF and PACF values have not been correlated across the Bartlett line, so it will be difficult to identify the model. Therefore, differencing is necessarily conducted again. The result of plot time series for the data, after the second differencing, is displayed in the figure below: 


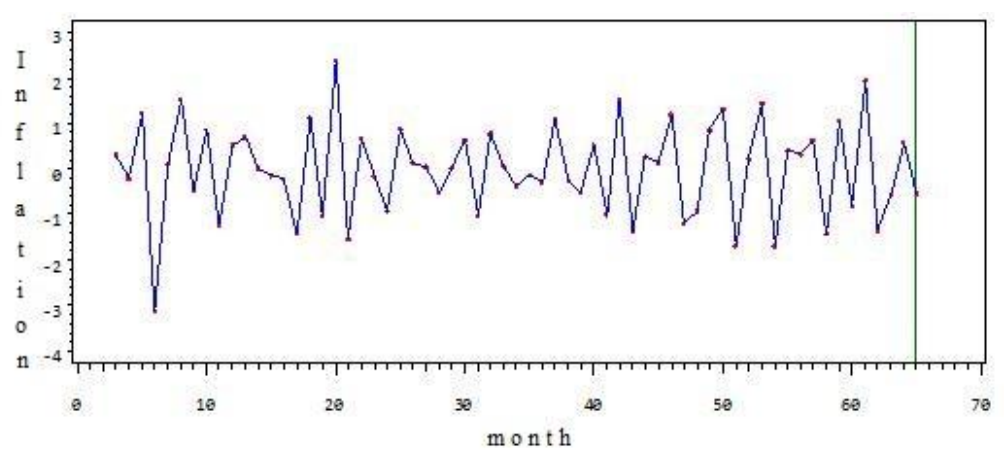

Figure 5 - Plot Time Series Data of the Second Differencing

The figure above shows that the second differencing of the data has shown a stationary pattern, since the data have been stationary, then the data can be used for the model identification step.

Model Identification. Inflation data that has been stationary then being checked for its ACF and PACF plots. Results of ACF and PACF plots of inflation data are used to estimate a temporary model. The ACF plot of inflation data is displayed in the following table.

Table 4 - ACF Plot of Inflation Data

\begin{tabular}{|c|c|c|c|c|c|}
\hline \multicolumn{6}{|c|}{ Autocorrelations } \\
\hline Lag & Covariance & Correlation & -198765443210 & 6 11233456678891 & Std Error \\
\hline 0 & 1.052069 & 1.00000 & & $|* * * * * * * * * * * * * * * * * * * *|$ & 0 \\
\hline 1 & -0.568407 & -.54028 & $* * * * * * * * * * * \mid$ & . & 0.125988 \\
\hline 2 & 0.037806 & 0.03594 &.$\quad$ & |* & 0.158555 \\
\hline 3 & -0.051162 & -.04863 & $* 1$ & . & 0.158684 \\
\hline 4 & 0.061637 & 0.05859 & . & |* & 0.158920 \\
\hline 5 & 0.056758 & 0.05395 & : & |* & 0.159263 \\
\hline 6 & -0.128355 & -.12200 & $* *$ & . & 0.159553 \\
\hline 7 & 0.082567 & 0.07848 & . & |** & 0.161027 \\
\hline 8 & 0.055423 & 0.05268 & . & |* & 0.161633 \\
\hline 9 & -0.173063 & -.16450 & . ${ }^{* * *}$ & . & 0.161905 \\
\hline 10 & 0.096810 & 0.09202 & . & ** & 0.164536 \\
\hline 11 & 0.021440 & 0.02038 & . & . & 0.165351 \\
\hline 12 & 0.031155 & 0.02961 & . & |* & 0.165391 \\
\hline 13 & 0.034381 & 0.03268 & . & |* & 0.165475 \\
\hline 14 & -0.233559 & -.22200 & ${ }^{* * * *}$ & . & 0.165578 \\
\hline 15 & 0.263420 & 0.25038 & . & |*****;. & 0.170237 \\
\hline
\end{tabular}

The ACF plot of inflation data in Figure 4.9 shows that the autocorrelation value is exit or cut after the lag 1 , so it can be concluded that statistically there is a significant correlation in lag 1. Next, PACF plot of inflation data is displayed in the following table:

Table 5 - PACF Plot of Inflation Data

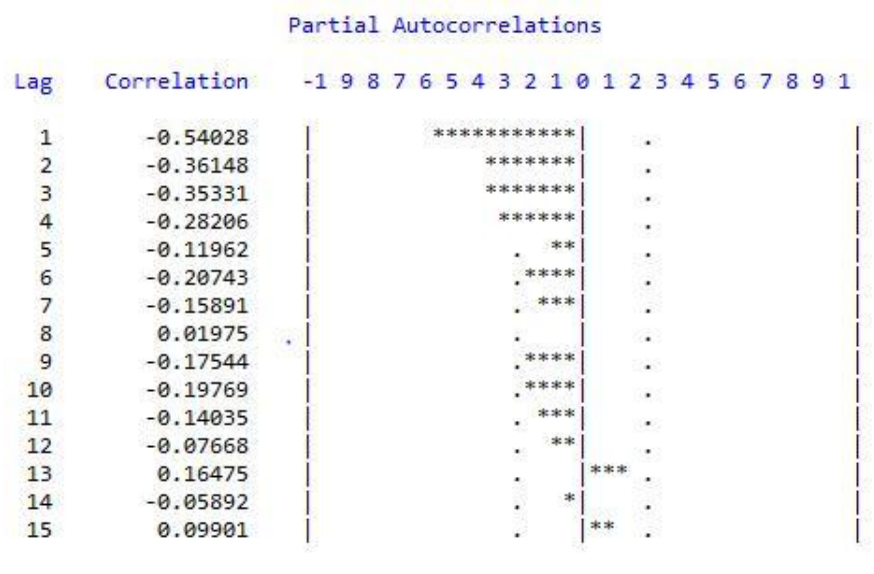

PACF plot of figure 4.10 shows that the PACF value is cut to the $4^{\text {th }}$ lag, then the estimation of appropriate model are ARIMA $(0,2,1)$, ARIMA $(1,2,0)$, ARIMA $(2,2,0)$, ARIMA $(3,2,0), \operatorname{ARIMA}(4,2,0), \operatorname{ARIMA}(1,2,1)$, ARIMA $(2,2,1), \operatorname{ARIMA}(3,2,1)$, and $\operatorname{ARIMA}(4,2,1)$. 
Estimation of Model Parameter. After the model is obtained, the next step is to estimate the parameter of the model. Summary of parameter estimation results for some appropriate model estimations can be seen in Table 6 .

Table 6 - Results of Model Parameter Estimation

\begin{tabular}{|c|c|c|c|c|}
\hline Model & Model Parameter & Coefficient & p-value & Description \\
\hline $\operatorname{ARIMA}(0,2,1)$ & $\theta_{1}$ & -0.97009 & $<0.0001$ & The model is significant \\
\hline $\operatorname{ARIMA}(1,2,0)$ & $\phi_{1}$ & 0.27107 & $<0.0266$ & The model is significant \\
\hline \multirow{2}{*}{$\operatorname{ARIMA}(2,2,0)$} & $\phi_{1}$ & 0.39782 & 0.0003 & \multirow{2}{*}{ The model is significant } \\
\hline & $\phi_{2}$ & -0.50789 & $<0.0001$ & \\
\hline \multirow{3}{*}{$\operatorname{ARIMA}(3,2,0)$} & $\phi_{1}$ & 0.40739 & 0.0017 & \multirow{3}{*}{ The model is not significant } \\
\hline & $\phi_{2}$ & -0.51366 & $<0.0001$ & \\
\hline & $\phi_{3}$ & 0.01707 & 0.8950 & \\
\hline \multirow{4}{*}{$\operatorname{ARIMA}(4,2,0)$} & $\phi_{1}$ & 0.41950 & 0.0010 & \multirow{4}{*}{ The model is not significant } \\
\hline & $\phi_{2}$ & -0.71741 & $<0.0001$ & \\
\hline & $\phi_{3}$ & 0.15133 & $<0.2738$ & \\
\hline & $\phi_{4}$ & -0.36338 & 0.0037 & \\
\hline \multirow{2}{*}{$\operatorname{ARIMA}(1,2,1)$} & $\phi_{1}$ & -0.45001 & 0.0025 & \multirow{2}{*}{ The model is not significant } \\
\hline & $\theta_{1}$ & -0.99999 & 0.8656 & \\
\hline \multirow{3}{*}{$\operatorname{ARIMA}(2,2,1)$} & $\phi_{1}$ & -0.27263 & 0.0361 & \multirow{3}{*}{ The model is not significant } \\
\hline & $\phi_{2}$ & -0.17763 & 0.1715 & \\
\hline & $\theta_{1}$ & -0.99252 & $<0.0001$ & \\
\hline \multirow{4}{*}{$\operatorname{ARIMA}(3,2,1)$} & $\phi_{1}$ & -0.34308 & 0.0201 & \multirow{4}{*}{ The model is not significant } \\
\hline & $\phi_{2}$ & -0.23499 & 0.0755 & \\
\hline & $\phi_{3}$ & -0.26354 & 0.0693 & \\
\hline & $\theta_{1}$ & -0.99995 & 0.8458 & \\
\hline \multirow{5}{*}{$\operatorname{ARIMA}(4,2,1)$} & $\phi_{1}$ & 1.08144 & $<0.0001$ & \multirow{5}{*}{ The model is significant } \\
\hline & $\phi_{2}$ & -0.96923 & $<0.0001$ & \\
\hline & $\phi_{3}$ & 0.51404 & 0.0037 & \\
\hline & $\phi_{4}$ & -0.35831 & 0.0062 & \\
\hline & $\theta_{1}$ & 0.75711 & $<0.0001$ & \\
\hline
\end{tabular}

Based on table 4.2, it can be seen that ARIMA $(0.2,1)$, ARIMA $(1,2,0)$, ARIMA $(2,2,0)$, and ARIMA $(4,2,1)$ models have been significant, since those models have $p$-values less than 0.05 . From these results, it can be concluded that temporary models that can be used for the next process are ARIMA $(0,2,1)$, ARIMA $(1,2,0), \operatorname{ARIMA}(2,2,0)$, and ARIMA $(4,2,1)$ models.

Diagnostic Check. Models whose parameters have been significant, subsequently performs a diagnostic check to see if the residual and the residual variance of the model meet the modeling assumptions. First, test is conducted to see whether the residual model is white noise or not. The test of residual white noise is conducted by using the statistic of Ljung Box test. Results Ljung Box Test can be seen in Table below.

Table 7 - Residual Results of Ljung Box Test

\begin{tabular}{|c|c|c|c|}
\hline Model & Up to lag & p-value & Description \\
\hline \multirow{2}{*}{$\operatorname{ARIMA}(0,2,1)$} & 6 & 0.3604 & \multirow{2}{*}{ White noise } \\
\hline & 12 & 0.5553 & \\
\hline \multirow{2}{*}{$\operatorname{ARIMA}(1,2,0)$} & 6 & 0.0062 & \multirow[b]{2}{*}{ Not white noise } \\
\hline & 12 & 0.0125 & \\
\hline \multirow{2}{*}{$\operatorname{ARIMA}(2,2,0)$} & 6 & 0.1658 & \multirow{2}{*}{ White noise } \\
\hline & 12 & 0.2626 & \\
\hline \multirow{2}{*}{$\operatorname{ARIMA}(4,2,1)$} & 6 & 0.4167 & \multirow{2}{*}{ White noise } \\
\hline & 12 & 0.3996 & \\
\hline
\end{tabular}

Based on the results obtained from Ljung Box test in table 4.2, it can be concluded that there are four models from the temporary model and there are three models of residual white noise: ARIMA $(0,2,1)$, ARIMA $(2,2,0)$ and ARIMA $(4,2,1)$ models. Residual model is also assumed to have normal distribution; therefore, residual normality test is conducted by using 
Kolmogorov-Smirnov test. The results of Kolmogorov-Smirnov test can be seen in Table below.

Table 8 - Results of Kolmogorov-Smirnov Test

\begin{tabular}{|c|c|c|c|}
\hline Model & Statistic Test & $\mathrm{p}$-value & Description \\
\hline ARIMA $(0,2,1)$ & 0.043267 & $>0.15$ & Residuals are normally distributed \\
\hline ARIMA $(1,2,0)$ & 0.081879 & $>0.15$ & Residuals are normally distributed \\
\hline ARIMA $(2,2,0)$ & 0.055423 & $>0.15$ & Residuals are normally distributed \\
\hline ARIMA $(4,2,1)$ & 0.058485 & $>0.15$ & Residuals are normally distributed \\
\hline
\end{tabular}

Table 8 shows that the four residual models tested have a normal distribution. From the results of diagnostic check that has been conducted before, it can be concluded that from the first estimation of four models, there are three temporary models that nearly meet the assumptions of ARIMA model $(0.2,1)$, ARIMA $(2,2,0)$ and ARIMA $(4,2.1)$. Next, the three models will be re-selected for one the best model that will be taken for forecasting.

Best Model Selection. From the three temporary models: ARIMA $(0,2,1)$, ARIMA $(2,2,0)$ and ARIMA $(4,2,1)$, the best model is the model that has the lowest forecasting value of MSE. The comparison results of forecasting results of MSE are shown in Table 9 below.

Table 9 - Results of MSE Forecasting

\begin{tabular}{|c|c|}
\hline Model & MSE Forecasting \\
\hline $\operatorname{ARIMA}(0,2,1)$ & 0.293764 \\
\hline $\operatorname{ARIMA}(2,2,0)$ & 0.395519 \\
\hline $\operatorname{ARIMA}(4,2,1)$ & 0.331832 \\
\hline
\end{tabular}

Based on the results in table 9 , it is known that the ARIMA model $(0.2,1)$ has the lowest MSE forecasting value of 0.293764 ; therefore it can be concluded that the best model for inflation forecast of housing, water, electricity, gas and fuel groups is ARIMA model $(0,2,1)$.

ARIMA $(0.2,1)$ model can be probabilistically written by the following equation:

$$
\begin{gathered}
(1-B)^{2} Z_{t}{ }^{*}=\left(1-\theta_{1} B\right) \varepsilon_{t} \\
\left(1-2 B+B^{2}\right) Z_{t}{ }^{*}=\left(1-\theta_{1} B\right) \varepsilon_{t} \\
Z_{t}{ }^{*}-2 Z_{t-1}{ }^{*}+Z_{t-2}{ }^{*}=\varepsilon_{t}-\theta_{1} \varepsilon_{t-1} \\
Z_{t}{ }^{*}=\varepsilon_{t}-\theta_{1} \varepsilon_{t-1}+2 Z_{t-1}{ }^{*}-Z_{t-2}{ }^{*} \\
\frac{1}{\sqrt{Z_{t}}}=\varepsilon_{t}-\theta_{1} \varepsilon_{t-1}+\frac{2}{\sqrt{Z_{t-1}}}-\frac{1}{\sqrt{Z_{t-2}}} \\
Z_{t}=\frac{1}{\left(\varepsilon_{t}-\theta_{1} \varepsilon_{t-1}+\frac{2}{\sqrt{Z_{t-1}}}-\frac{1}{\sqrt{Z_{t-2}}}\right)^{2}} \\
Z_{t}{ }^{*}=\frac{1}{\sqrt{Z_{t}}}
\end{gathered}
$$

So, the equation of ARIMA $(0,2,1)$ model for inflation value of expenditure groups od housing, electricity, water, gas, and fuel is:

$$
Z_{t}=\frac{1}{\left(\varepsilon_{t}+0,97009 \varepsilon_{t-1}+\frac{2}{\sqrt{Z_{t-1}}}-\frac{1}{\sqrt{Z_{t-2}}}\right)^{2}}
$$




\section{CONCLUSION AND SUGGESTIONS}

Based on the results of the research and discussion that have been described in the previous chapters, it can be drawn some conclusions as follows:

The best model that can be used for Indonesian's monthly inflation forecast for expenditure groups of housing, water, electricity, gas and fuel is ARIMA $(0,2,1)$ model.

The equation of ARIMA $(0.2,1)$ model for Indonesian's monthly inflation forecast for expenditure groups of housing, water, electricity, gas and fuel is:

$$
Z_{t}=\frac{1}{\left(\varepsilon_{t}+0,97009 \varepsilon_{t-1}+\frac{2}{\sqrt{Z_{t-1}}}-\frac{1}{\sqrt{Z_{t-2}}}\right)^{2}}
$$

The forecasting value of MSE of ARIMA $(0,2,1)$ model is 0.293764 .

The value of inflation is often fluctuating and is influenced by many external factors; for example, the hikes of fuel price, the changes of socio-political policy, natural disasters etc. Therefore, the forecasting of inflation value for further research is suggested to use time series analysis approach which includes other external factors, such as transfer function model, intervention, etc.

\section{REFERENCES}

1. Akbarwati, I, 2015, Inflasi Indonesia Paling Tinggi di ASEAN, http://vibiznews .com/2015/01/06/inflasi-indonesia-paling-tinggi-di-asean/, 11 Februari 2015.

2. Badan Pusat Statistik Indonesia (BPS), 2014, Inflasi, http://bps.go.id/tabsub/view.php?kat =2\&tabel=1\&daftar=1\&id_subyek=03\&notab=1, 7 November 2014.

3. Cahyuni, I., 2012, Analisis Peramalan Inflasi di Jawa Timur Khusus Bahan Makanan dengan Menggunakan Pendekatan Regresi Variabel Dummy dan ARIMA, Thesis, Fakultas Matematika dan IImu Pengetahuan Alam Institut Teknologi Sepuluh Nopember, Surabaya.

4. Faust, J., \& Wright, J. H. (2013). Forecasting inflation. Handbook of economic forecasting, 2(Part A), 3-56.

5. Lusia, D. A. dan Suhartono, 2011, Peramalan Inflasi dengan Metode Weighted Fuzzy Time Series, Thesis, Fakultas Matematika dan IImu Pengetahuan Alam Institut Teknologi Sepuluh Nopember, Surabaya.

6. McCleary, R., Hay, R. A., Meidinger, E. E., \& McDowall, D. (1980). Applied time series analysis for the social sciences. Beverly Hills, CA: Sage Publications.

7. Stock, J. H., \& Watson, M. W. (1999). Forecasting inflation. Journal of Monetary Economics, 44(2), 293-335.

8. Tzavalis, E., \& Wickens, M. R. (1996). Forecasting inflation from the term structure. Journal of Empirical Finance, 3(1), 103-122.

9. Wibowo, S. H., 2014, Pengaruh Penyesuaian Tarif Tenaga Listrik Golongan Rumah Tangga Terhadap Inflasi, Badan Pusat Statistik Indonesia, Jakarta. 